\title{
Altered mucosal DNA methylation in parallel with highly active Helicobacter pylori-related gastritis
}

\author{
Takeichi Yoshida $\cdot$ Jun Kato $\cdot$ Takao Maekita $\cdot$ Satoshi Yamashita $\cdot$ Shotaro Enomoto $\cdot$ Takayuki Ando $\cdot$ \\ Tohru Niwa $\cdot$ Hisanobu Deguchi $\cdot$ Kazuki Ueda $\cdot$ Izumi Inoue $\cdot$ Mikitaka Iguchi • Hideyuki Tamai • \\ Toshikazu Ushijima • Masao Ichinose
}

Received: 5 September 2012/ Accepted: 17 December 2012/Published online: 6 January 2013

(c) The International Gastric Cancer Association and The Japanese Gastric Cancer Association 2013

\begin{abstract}
Background Chronic inflammation triggered by Helicobacter pylori causes altered DNA methylation in stomach mucosae, which is deeply involved in gastric carcinogenesis. This study aimed to elucidate the correlation between altered mucosal DNA methylation levels and activity of H. pylori-related gastritis, because inflammatory activity shows particular correlations with the development of diffuse-type cancer.

Methods Methylation levels in stomach mucosae of 78 healthy volunteers were determined by real-time methylation-specific PCR or bisulfite pyrosequencing. Examined loci were the promoter $\mathrm{CpG}$ islands of six genes (FLNC, HANDI, THBD, p4IARC, HRASLS, and LOX) and the CpG sites of non-coding repetitive elements (Alu and Sat $\alpha$ ) that are reportedly altered by $H$. pylori infection. Activity of $H$. pylori-related gastritis was evaluated using two serum markers: H. pylori antibody titer and pepsinogen II.

Results Methylation levels of the six $\mathrm{CpG}$ islands were consistently increased, and those of the two repetitive elements were consistently decreased in a stepwise manner with the activity of gastric inflammation as represented by serum marker levels. Each serum marker level was well correlated with the overall DNA methylation status of
\end{abstract}

T. Yoshida $(\bowtie) \cdot$ J. Kato $\cdot$ T. Maekita $\cdot$ S. Enomoto

H. Deguchi - K. Ueda - I. Inoue - M. Iguchi - H. Tamai ·

M. Ichinose

Second Department of Internal Medicine, Wakayama Medical

University, 811-1 Kimiidera, Wakayama,

Wakayama 641-0012, Japan

e-mail: tayoshid@wakayama-med.ac.jp

S. Yamashita $\cdot$ T. Ando $\cdot$ T. Niwa $\cdot$ T. Ushijima

Division of Epigenomics, National Cancer Center Research

Institute, 5-1-1 Tsukiji, Chuo-ku, Tokyo 104-0045, Japan stomach mucosa, and these two serologic markers were additive in the detection of the mucosa with severely altered DNA methylation.

Conclusions Alteration in mucosal DNA methylation level was closely correlated with activity of $H$. pylorirelated gastritis as evaluated by serum markers. The observed correlation between altered DNA methylation levels and activity of $H$. pylori-related gastritis appears to be one of the relevant molecular mechanisms underlying the development of diffuse-type cancer.

Keywords Gastric cancer - Helicobacter pylori . Carcinogenesis - Active gastritis · DNA methylation
Abbreviations
UC Ulcerative colitis
H. pylori Helicobacter pylori
PG Pepsinogen
CGI CpG island

\section{Introduction}

Epidemiological studies have revealed that long-lasting inflammation in specific organs is associated with increased risks of cancers, such as ulcerative colitis (UC)associated colon cancer [1], liver cancer [2], and gastric cancer [3]. Accumulation of genetic and epigenetic alterations induced by chronic inflammation appears to contribute to cancer development [4]. In addition, activity of chronic inflammation has been shown to be associated with the incidence of cancer development [5-7]. In longstanding UC, patients with highly active inflammation during the disease course are more likely to develop 
dysplasia or cancer than those without [5]. Likewise, in viral hepatitis, patients with high serum alanine aminotransferase levels are more likely to develop hepatocellular carcinoma than those without $[6,7]$.

In stomach mucosae, chronic inflammation is triggered by Helicobacter pylori (H. pylori) infection and causes a predisposition toward gastric cancer development [8]. In terms of correlations between activity of $H$. pylori-related gastritis and incidence of gastric cancer, two serum markers have been evaluated: $H$. pylori antibody and pepsinogen (PG) II $[9,10]$. Both the titer of serum H. pylori antibody, which is usually used for determining the current status of the bacterial infection, and PG II, an aspartic protease also known as an inactive precursor of pepsin $\mathrm{C}$ produced mainly by the stomach mucosae, have been shown to correlate with the activity of $H$. pylori-related gastritis [11, 12]. In addition, our previous reports have indicated that individuals with $H$. pylori antibody titers $>500 \mathrm{U} / \mathrm{ml}$ or PG II levels $>30 \mathrm{ng} / \mathrm{ml}$ are at high risk of developing gastric cancer, particularly diffuse-type cancer according to Lauren's histopathological classification [10, 13]. Ito et al. [14] also reported that patients with PG II $>30 \mathrm{ng} / \mathrm{ml}$ show an increased risk of diffuse-type gastric cancer.

DNA methylation is a covalent chemical modification resulting in the addition of a methyl group at the $\mathrm{C5}$ position of cytosine in the sequence context $5^{\prime}-\mathrm{CG}-3^{\prime}$ [15]. This epigenetic effect plays pivotal roles in carcinogenesis $[16,17]$. In the context of cancer development and progression, two types of DNA methylation have been identified: $\mathrm{CpG}$ island (CGI) hypermethylation and global hypomethylation [18]. CGI hypermethylation occurs within promoter CGIs and is often associated with a loss of protein expression by transcription repression [19]. On the other hand, global hypomethylation, which is observed in repetitive elements such as Alu, LINE-1, and Sat $\alpha$ has been shown to be associated with genomic instability [20, 21].

DNA methylation is also deeply involved in chronic inflammation-mediated carcinogenesis. As shown in our previous studies [22, 23], aberrant DNA methylation has been observed in $H$. pylori-infected stomach mucosae as well as liver with viral infection [24] or colorectal mucosae with UC [25]. Altered DNA methylation in noncancerous inflammatory tissues has been considered to be one of the early steps toward neoplastic change. The accumulation of DNA methylation along with inflammation contributes to the development of cancer, according to the hypothesis of 'an epigenetic field for cancerization' [17, 26].

A recent study showed a correlation between highly active inflammation and altered mucosal DNA methylation in UC [27]. That report suggested that higher methylation levels induced by active inflammation were associated with inflammation-related cancer development. In contrast, correlations between activity of gastritis and altered mucosal DNA methylation levels have not been reported. Activity of gastritis is reportedly correlated with the development of diffuse-type gastric cancer [10, 13]. We therefore hypothesized that the degree of altered DNA methylation in stomach mucosae is correlated with activity of gastritis, since methylation observed in inflammatory stomach mucosae would directly or indirectly induce diffuse-type cancer development.

This study therefore aimed to clarify whether aberrant DNA methylation levels are correlated with inflammation activity in $H$. pylori-infected stomach mucosae. To this end, we measured and evaluated methylation levels of promoter CGIs of six genes (FLNc, HAND1, THBD, p4lARC, HRASLS, and $L O X$ ), and two repetitive elements (Alu and Sat $\alpha$ ), all of which have been shown to be hyperor hypomethylated in $H$. pylori-related gastritis in our previous reports [22, 28] in human stomach mucosae according to the inflammation status evaluated by H. pylori-antibody titers and serum PG II levels.

\section{Materials and methods}

\section{Cases, samples, and DNA extraction}

Seventy-eight healthy volunteers were recruited after providing informed consent during an endoscopic screening program for gastric cancer under the approval of the Institutional Review Board of Wakayama Medical University. Fast blood samples were collected as part of the routine laboratory tests. Aliquots of the separated sera were stored below $-20{ }^{\circ} \mathrm{C}$ until use. All study subjects were confirmed to be free from any previous history of gastric cancer, surgical resection of the stomach, or chronic renal failure. Subjects likewise had no history of $H$. pylori eradication therapy and had not been prescribed medications that might affect gastrointestinal function, such as proton pump inhibitors, adrenocortical steroids, or nonsteroidal antiinflammatory drugs. Stomach mucosae samples were collected by endoscopic biopsy of the antral and the corpus regions in the lesser curvature with sterilized biopsy forceps (Olympus, Tokyo, Japan), immediately frozen in liquid nitrogen, and stored at $-80{ }^{\circ} \mathrm{C}$ until extraction of genomic DNA. High molecular weight DNA was extracted using the phenol/chloroform method.

Serologic analysis

Anti-H. pylori immunoglobulin (Ig)G antibody titers were measured using an enzyme-linked immunosorbent assay (ELISA) (MBL, Nagoya, Japan). Subjects with antibody titers $>50 \mathrm{U} / \mathrm{ml}$ were classified as $H$. pylori positive, and 
those with antibody titers $50 \mathrm{U} / \mathrm{ml}$ were regarded as infection negative. The $H$. pylori-positive group was further divided into two groups according to the antibody titer: $500 \mathrm{U} / \mathrm{ml}$ as a low-titer group and $>500 \mathrm{U} / \mathrm{ml}$ as a hightiter group.

Serum pepsinogen levels were measured using PG I/PG II RIA-based kits (Dainabbot, Tokyo, Japan), which involved a modified radioimmunoassay method that we previously established [29]. Subjects were divided into three groups according to PG II level: group II-0, PG II $\leq 10 \mathrm{ng} / \mathrm{ml}$; group II-10, PG II $>10 \mathrm{ng} / \mathrm{ml}$ and $\leq 30 \mathrm{ng} / \mathrm{ml}$; group II-30, PG II $>30 \mathrm{ng} / \mathrm{ml}$. These thresholds were determined in a previous study according to the risk of gastric cancer [13].

Sodium bisulfite modification, quantitative real-time methylation-specific PCR, and bisulfite pyrosequencing

Bisulfite modification was performed using $1 \mu \mathrm{g}$ of BamHI-digested genomic DNA as previously described [30]. The modified DNA was suspended in $40 \mu \mathrm{l}$ of TrisEDTA buffer, and an aliquot of $1 \mu \mathrm{l}$ was used for quantitative real-time methylation-specific PCR (qMSP) and bisulfite pyrosequencing.

The qMSP was performed as described previously [22]. Briefly, real-time PCR with a primer set specific to methylated (M) or unmethylated (U) sequences was undertaken using SYBR ${ }^{\circledR}$ Green I (BioWhittaker Molecular Applications, Rockland, ME, USA) and an iCycler Thermal Cycler (Bio-Rad Laboratories, Hercules, CA, USA). Standard DNA was prepared by cloning PCR products into the pGEM-T Easy vector (Promega, Madison, WI, USA). The number of molecules in a sample was determined by comparing its amplification with those of standard DNA that contained exact numbers of molecules $\left(10^{1}-10^{6}\right.$ molecules). Based on the numbers of $M$ molecules and $U$ molecules for a genomic region, a methylation level of the region was calculated as the fraction of $M$ molecules among the total number of DNA molecules (no. of $\mathrm{M}$ molecules + no. of $U$ molecules).

Bisulfite pyrosequencing was performed as described previously [28]. Briefly, biotinylated PCR product with designed bisulfite PCR primers was purified and made single stranded. PCR products were bound to streptavidincoated Sepharose beads, purified, washed, and denatured using a $0.2 \mathrm{ml} / \mathrm{l}$ of $\mathrm{NaOH}$ solution. Thereafter, those products were annealed to $0.2 \mu \mathrm{M}$ pyrosequencing primers, and pyrosequencing was undertaken using the PSQ 96 Pyrosequencing System (Qiagen, Valencia, CA, USA). A methylation level was obtained using PSQ Assay Design software (Qiagen). The primers used in qMSP and bisulfite pyrosequencing have been described in previous reports $[22,28]$.
The methylation score was determined as 1,2 , or 3 at each locus according to the methylation level: 1 , degree of altered methylation within the lowest one-third of all subjects; 3, degree of altered methylation within the highest one-third, with the remaining categorized as 2 . Comprehensive methylation status of each individual was determined by accumulating 'the methylation score' of six CGIs and three loci of two repetitive elements.

Statistical analysis

Correlations between serum $H$. pylori antibody titers and serum PG II levels were analyzed using Spearman's rank correlation coefficient. Differences in median methylation levels among the three groups according to serum levels of H. pylori antibody titer or PG II were analyzed using the Kruskal-Wallis test. When the Kruskal-Wallis test showed a significant difference, a multiple comparison was performed using the Steel-Dwass test. All analyses were performed using JMP version 9.0 software (SAS Institute, Cary, NC, USA), and the results were considered significant for values of $p<0.05$.

\section{Results}

Background characteristics of the individuals analyzed

Median age for the 78 examined individuals was 55 years (range 23-91 years), and 39 individuals (50\%) were male. Other background characteristics of the participants are presented in Table 1. H. pylori antibody titers and serum

Table 1 Background characteristics of the individuals

\begin{tabular}{ll}
\hline & All individuals $(N=78)$ \\
\hline $\begin{array}{l}\text { Age (years) } \\
\text { Gender }\end{array}$ & $55(23-91)$ \\
Male & $39(50 \%)$ \\
Female & $39(50 \%)$ \\
H. pylori antibody titer & \\
Negative $(\leq 50 \mathrm{U} / \mathrm{ml})$ & $37(47 \%)$ \\
Low titer $(>50, \leq 500 \mathrm{U} / \mathrm{ml})$ & $28(36 \%)$ \\
High titer $(>500 \mathrm{U} / \mathrm{ml})$ & $13(17 \%)$ \\
PG II level & \\
II-0 $(\leq 10 \mathrm{U} / \mathrm{ml})$ & $27(35 \%)$ \\
II-10 $(>10, \leq 30 \mathrm{U} / \mathrm{ml})$ & $36(46 \%)$ \\
II-30 $(>30 \mathrm{U} / \mathrm{ml})$ & $15(19 \%)$
\end{tabular}

H. pylori Helicobacter pylori, PG II pepsinogen II

a Value is median (range) 
PG II levels of subjects were measured. As both of these two markers were expected to reflect the activity of inflammation in the stomach mucosae, a significant correlation was observed between the two serologic markers in these 78 subjects (Spearman's rank correlation coefficient, $0.49 ; p<0.05)$.
Mucosal DNA methylation levels in stomach and serum H. pylori antibody titers

Methylation levels in the stomach mucosae of the 78 subjects were determined. Six promoter CGIs (FLNc, HAND1, THBD, p4IARC, HRASLS, and LOX) and two non-coding a

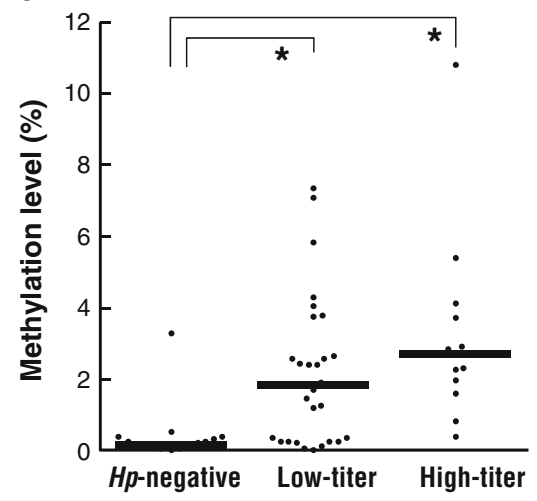

FLNc

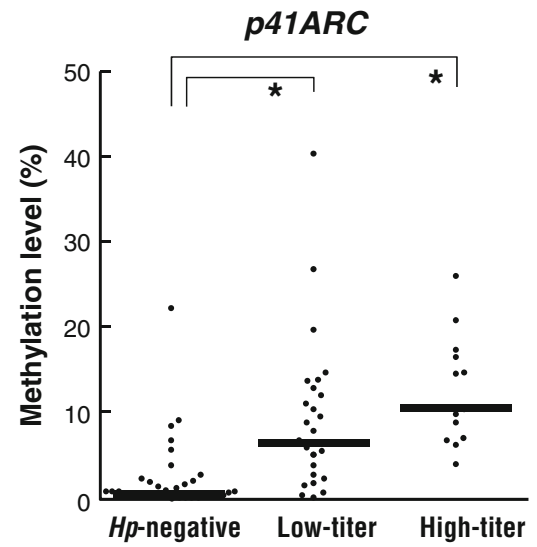

b

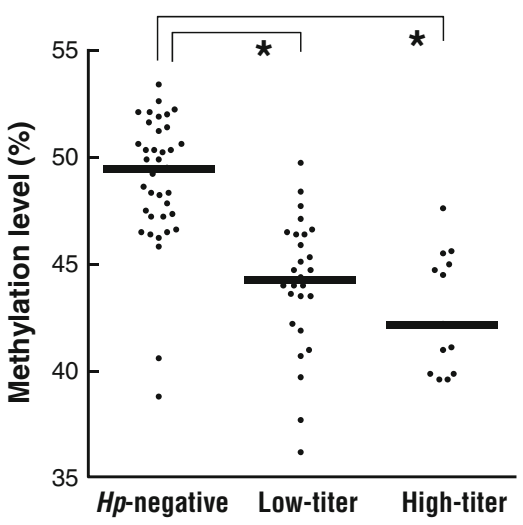

HAND1

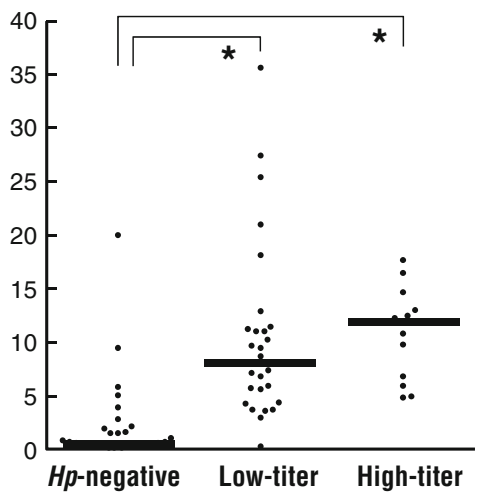

HRASLS

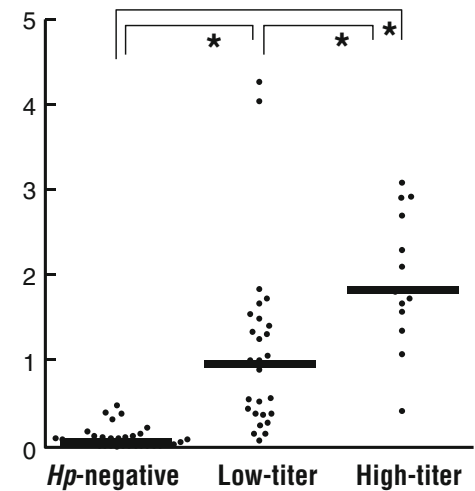

ALU2

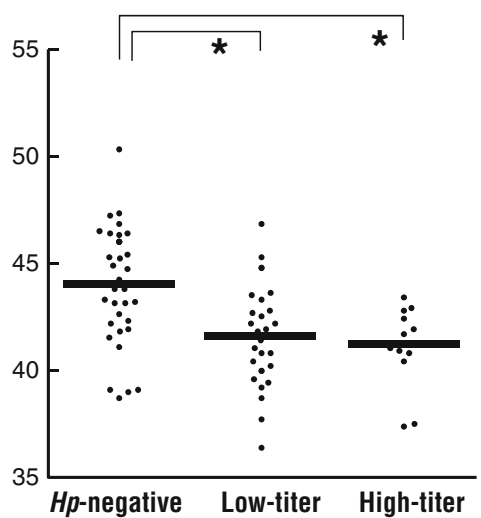

THBD
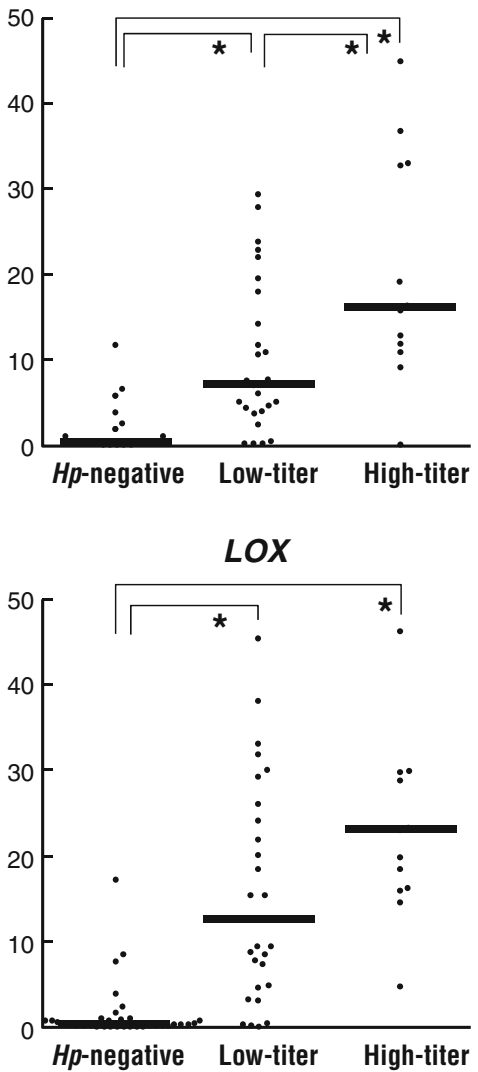

Fig. 1 Methylation levels of the promoter $\mathrm{CpG}$ islands of six genes (a) and two repetitive DNA elements (b) in the antral region of the gastric mucosae of the 78 subjects according to serum $\mathrm{H}$. pylori antibody titer. Compared to the $H$. pylori-negative group, the methylation level was consistently increased ( $\mathrm{CpG}$ island hypermethylation) or decreased (hypomethylation in repetitive elements) in a stepwise manner in the low- and high-titer groups $(p<0.05)$ 

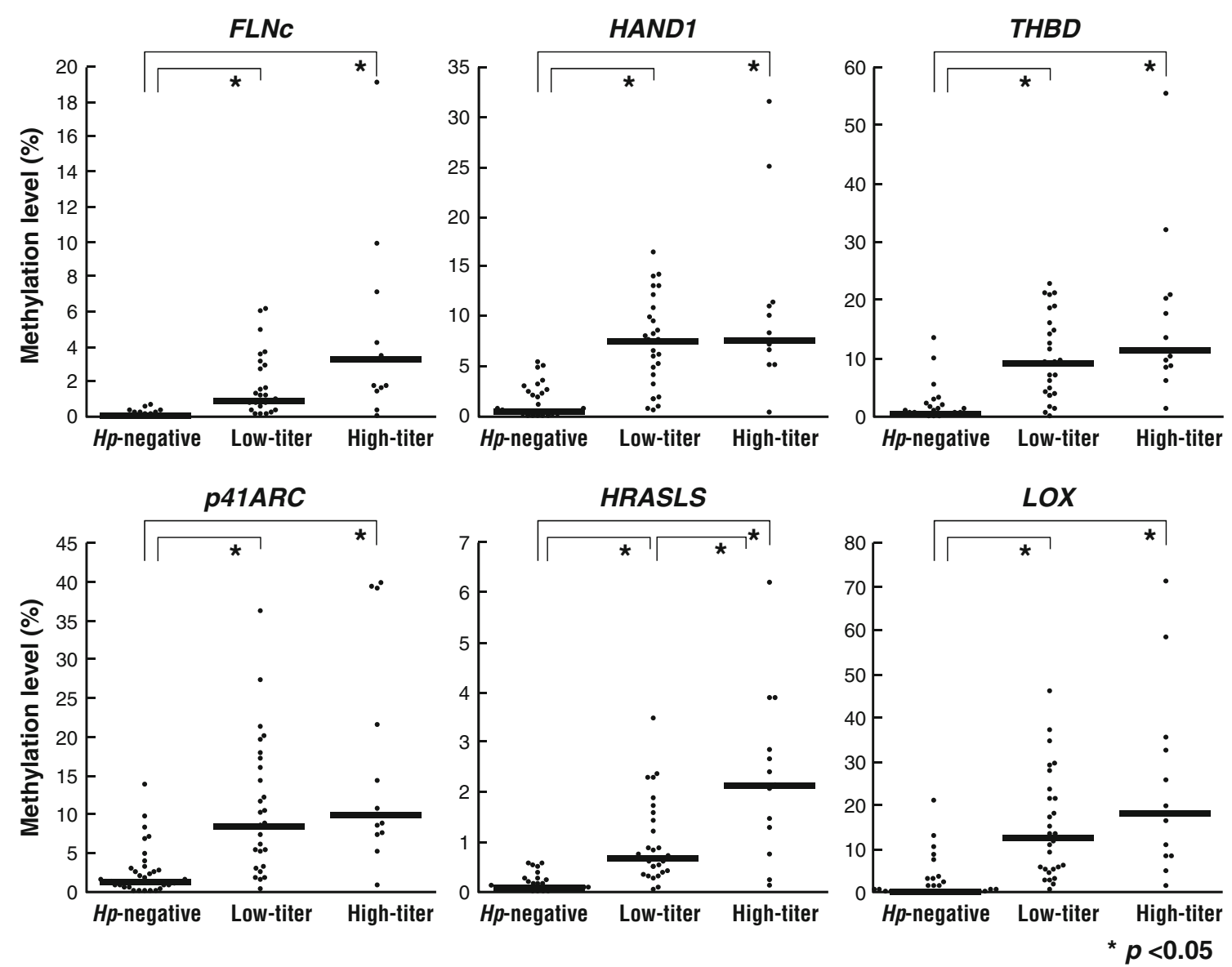

Fig. 2 Methylation levels of the promoter $\mathrm{CpG}$ islands of six genes in the corpus region of the gastric mucosae according to serum $H$. pylori antibody titer. Compared to the $H$. pylori-negative group,

repetitive elements (Alu and Sat $\alpha$ ) were examined by qMSP and bisulfite pyrosequencing, respectively.

Methylation levels of the CGIs were consistently increased in a stepwise manner with elevations of $H$. pylori antibody titer (Kruskal-Wallis test: $p<0.05$ ) in both of the antral (Fig. 1a) and corpus regions (Fig. 2). At all examined loci, methylation levels in $H$. pylori-negative subjects were at or around $0 \%$ (from $0.0 \%$ at $F L N c$ to $0.71 \%$ at p4IARC in the antral region and from $0.0 \%$ at $F L N c$ to $1.23 \%$ at $p 41 A R C$ in the corpus region), while methylation levels in the low-titer group were significantly higher to variable extents (from $1.0 \%$ at HRASLS to $12.4 \%$ at $L O X$ in the antral region and from $0.7 \%$ at HRASLS to $12.3 \%$ at $L O X$ in the corpus region) (Steel-Dwass test: $p<0.05$ ). In addition, methylation levels at each locus in the hightiter group were elevated 1.5- to 2.3-fold in the antral region and 1.0- to 3.5-fold in the corpus region compared to those in the low-titer group, although significant differences were only observed at THBD and HRASLS in the antral region and only at $H R A S L S$ in the corpus region (Steel-Dwass test: $p<0.05$ ). the methylation level was consistently increased in a stepwise manner in the low- and high-titer groups $(p<0.05)$

As for repetitive elements of Alu and Sata, methylation levels were consistently reduced in a stepwise manner with the elevation of $H$. pylori antibody titers in the antral region (Fig. 1b) (Kruskal-Wallis test: $p<0.05$ ). Differences in methylation level at all these loci in the antral region were significant both between the $H$. pylori-negative and lowtiter groups and between the $H$. pylori-negative and hightiter groups (Steel-Dwass test: $p<0.05$ ). A similar trend was also observed with analysis using the samples of the corpus regions (data not shown), although the statistical significance could not be confirmed because of the smaller number of samples.

Mucosal DNA methylation levels in stomach and serum PG II levels

Correlations between DNA methylation levels and serum PG II levels were analyzed. Methylation levels at the CGIs were consistently increased in a stepwise manner with elevations in PG II level, as observed in the correlation with $H$. pylori antibody titers (Kruskal-Wallis test: $p<0.05$ ) in both of the 
antral (Fig. 3a) and corpus regions (Fig. 4). However, differences between group II-10 and group II-30 were inconspicuous and not significant at any of the six loci.

Methylation levels of repetitive elements at Alu and Sat $\alpha$ were consistently reduced in a stepwise manner with elevations in PG II level, although the difference at Sat $\alpha$ was not significant (Kruskal-Wallis test) (Fig. 3b).

Serum PG levels are generally used for the detection of H. pylori-infection related atrophic gastritis on the basis of the previously described PG test positive criteria (PG I a

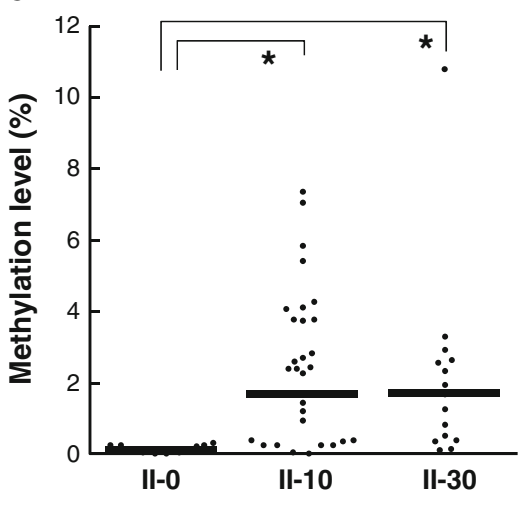

p41ARC

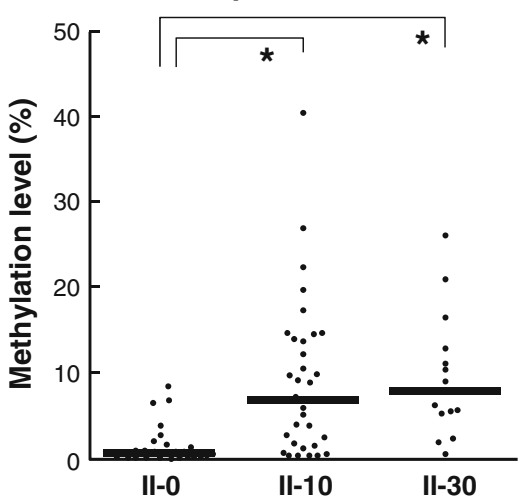

HAND1

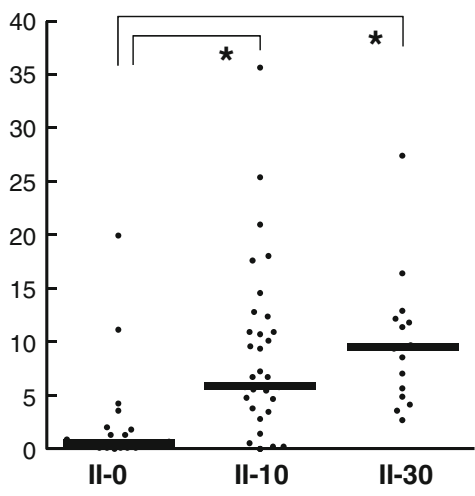

HRASLS

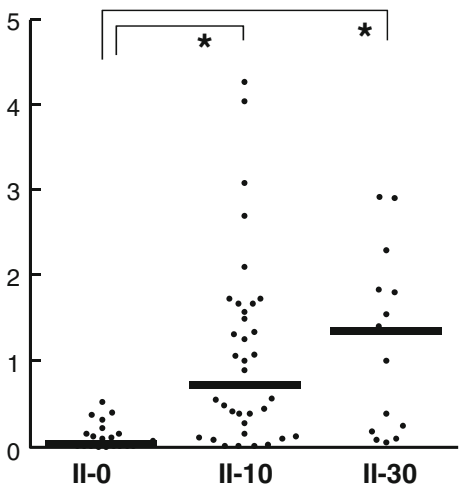

THBD

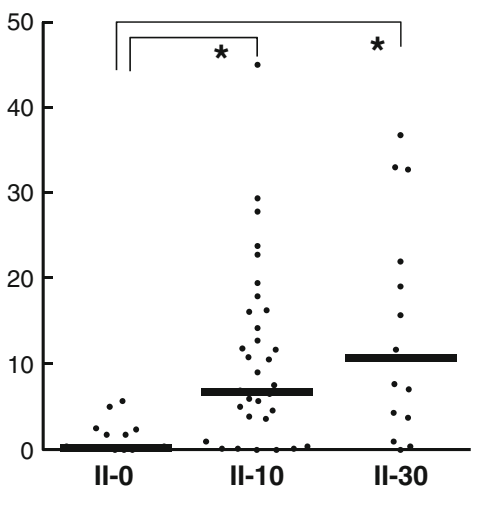

LOX

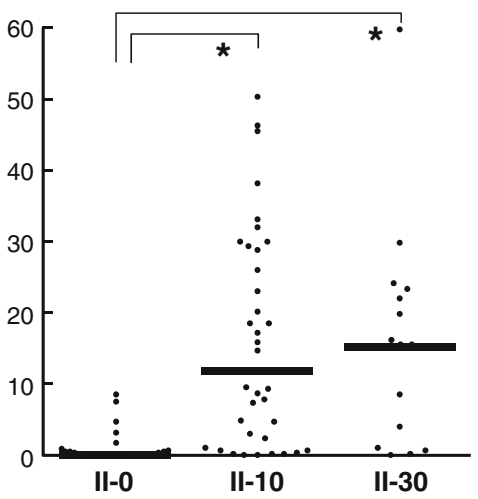

b

ALU1

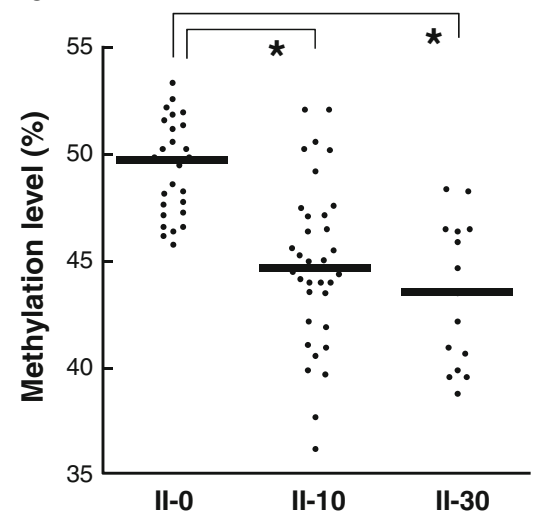

ALU2

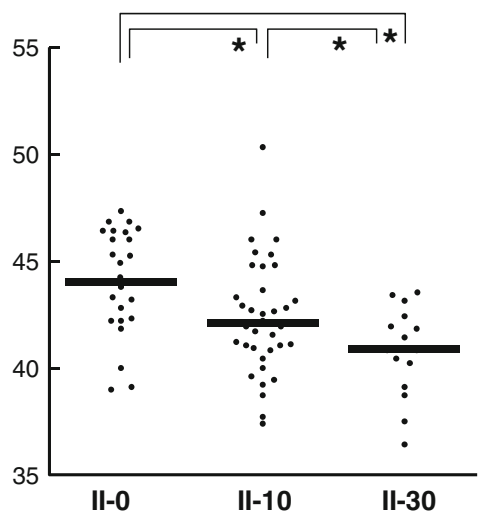

SAT $\alpha$

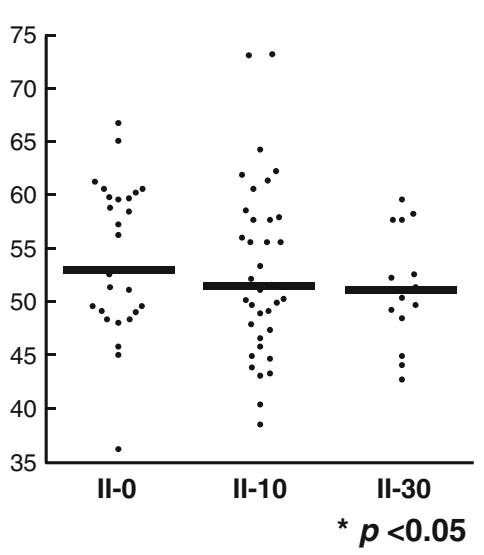

Fig. 3 Methylation levels of promoter $\mathrm{CpG}$ islands of six genes (a) and two repetitive DNA elements (b) in the antral region of the gastric mucosae of the 78 subjects according to serum pepsinogen II levels. Compared to group II-0, the methylation level was consistently increased ( $\mathrm{CpG}$ island hypermethylation) or decreased (hypomethylation in repetitive elements) in a stepwise manner in group II-10 and group II-30 $(p<0.05)$ 

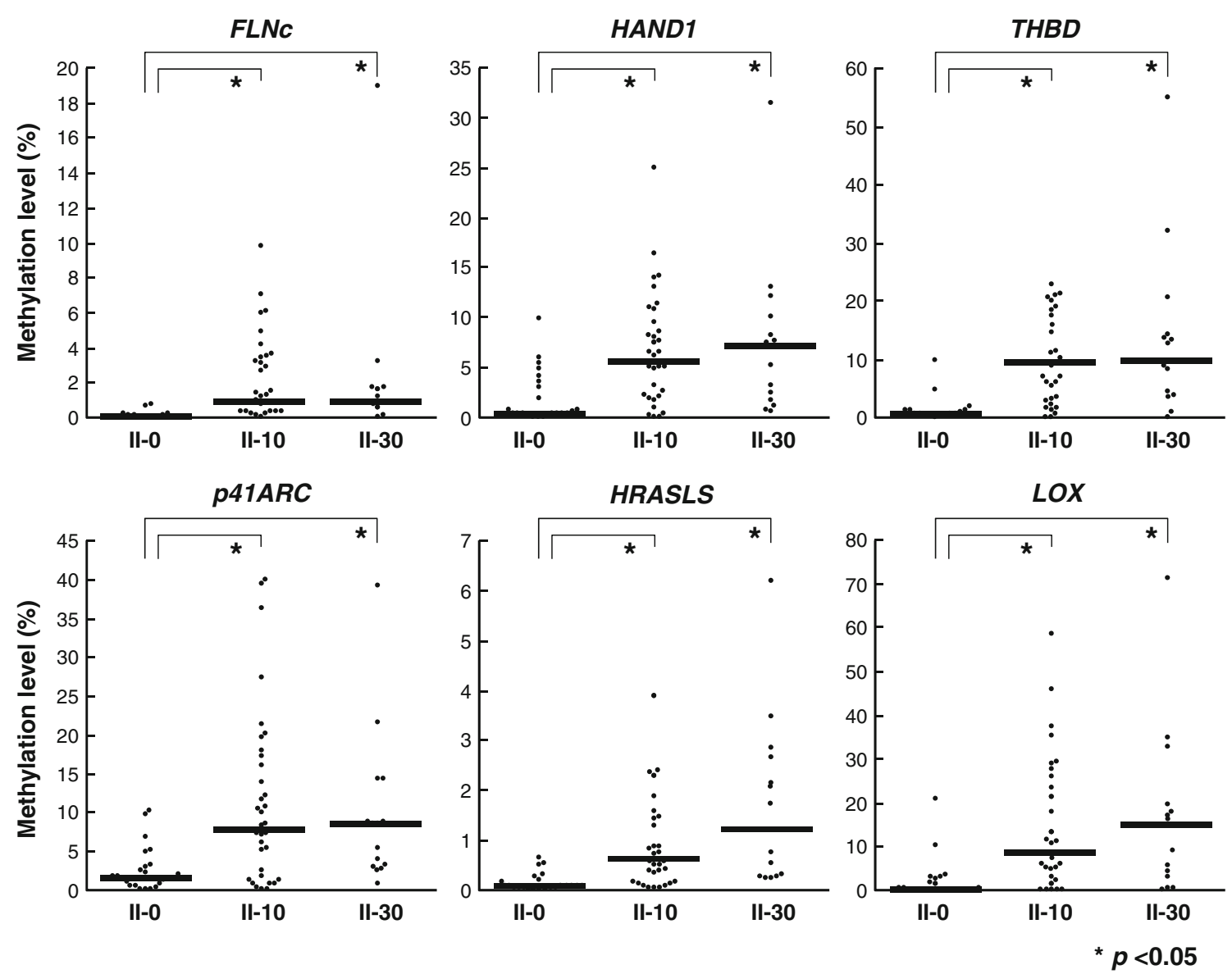

Fig. 4 Methylation levels of the promoter $\mathrm{CpG}$ islands of six genes in the corpus region of the gastric mucosae according to serum H. pylori antibody titer. Compared to the H. pylori-negative group,

$\leq 70 \mathrm{ng} / \mathrm{ml}$ and PG I/II ratio $\leq 3.0$ ) [10]. Then we compared with methylation levels between subjects with and without gastric atrophy according to the criteria. Among the 41 H. pylori-infected subjects (low-titer group and high-titer group), 19 subjects were classified as those with atrophic gastritis. The median methylation levels were not affected by the presence or absence of atrophy. The methylation levels in the high PG II subjects (group II-30) were also similar between the subjects with and without atrophy.

Spectrum of methylation status for individual subjects

Lastly, we comprehensively overviewed the methylation status and serum markers of all participating individuals. Methylation status was stratified proportionally into three categories (high, middle, and low) according to the accumulated methylation scores of the nine examined loci as mentioned in the "Materials and methods."

Methylation status based on the nine analyzed sites was in parallel with serum markers (Fig. 5). These results also indicated discrepancies in methylation levels between the methylation level was consistently increased in a stepwise manner in the low- and high-titer groups $(p<0.05)$

grades of gastritis activity as evaluated by each of the two serum markers, particularly among subjects in the middle category of methylation. Furthermore, the stratification of methylation levels at each site by serum levels of PG II and H. pylori antibody titer allowed identification of a group showing more severely altered methylation in $77.8 \%(7 / 9)$ of the analyzed sites; these two serological markers were additive for the detection of the mucosa displaying highly altered DNA methylation in these sites.

\section{Discussion}

The present results clearly indicated that active $H$. pylorirelated gastritis induces alteration in DNA methylation evenly in various CGIs and repetitive elements. Observed levels of altered DNA methylation increased in a stepwise manner with increases in serum levels of PG II or H. pylori antibody titers as markers of active gastritis [12, 31]. Many reports have examined altered DNA methylation in inflammatory tissues in terms of cancer risk in the fields of 


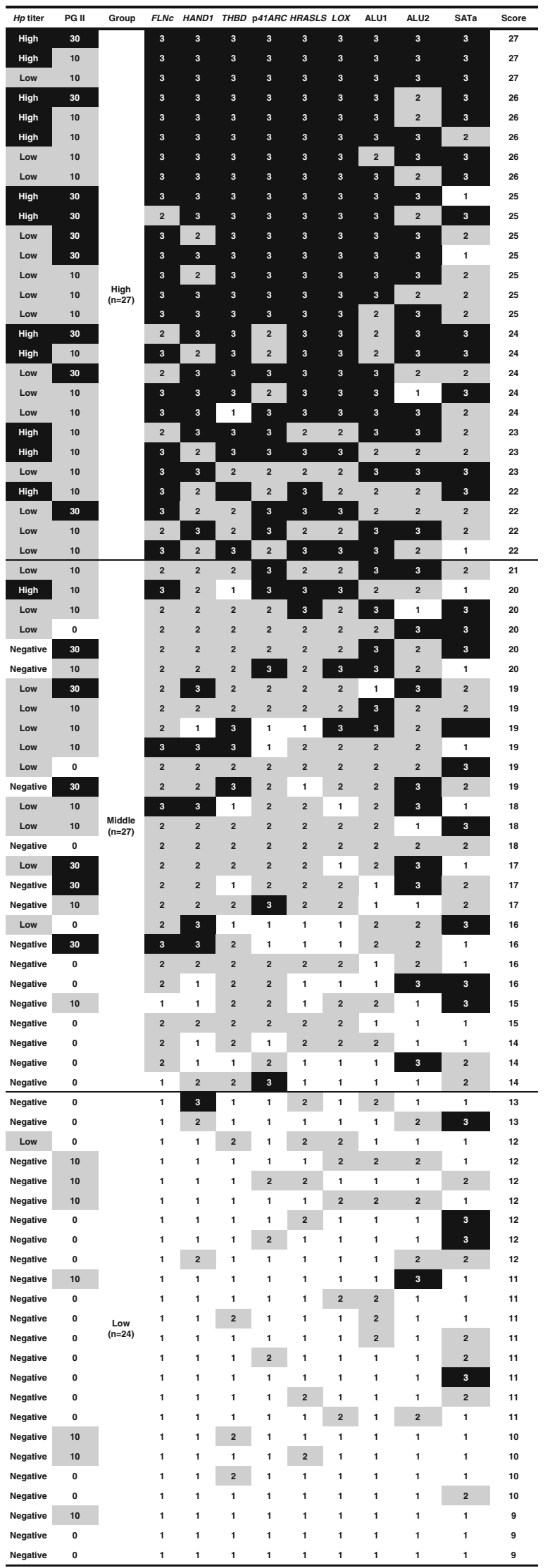

4 Fig. 5 Comprehensive view of methylation status and the two serum markers among individual participants. As a whole, methylation status paralleled serum markers in each individual

viral hepatitis, UC, and $H$. pylori-related gastritis [32-34]. However, attention has rarely been paid to the correlations between the degree of altered DNA methylation and activity of inflammation, probably because of difficulties in quantitatively evaluating inflammation in tissues. The diagnosis of gastritis is based on histopathology of the stomach mucosa. However, since H. pylori-related gastritis is a multifocal process, it is difficult to accurately diagnose the degree of active inflammation in the whole stomach based on a few endoscopic biopsy samples. Furthermore, histological diagnosis of gastritis depends on subjective judgment without a gold standard [35]. The present study therefore used two serum tests as more objective surrogate markers of gastric inflammation, and this is the first report to show a close correlation between the activity of gastritis as reflected by these two serum markers and the degree of altered methylation.

The antibody titers of the two serum markers, PG II and H. pylori, were additive in the detection of mucosa with severely altered DNA methylation. In addition, discrepancies were apparent between grades of serum levels of the two markers, particularly among subjects with mucosal DNA methylation categorized as middle grade. These results suggest that differences exist in inflammatory status as identified by each of these two markers; while $H$. pylori antibody levels reflect the complex interactions between bacterial infection and immunological host response, PG II levels are considered to reflect local mucosal reaction. These two serum tests thus appear to reflect two different aspects of $H$. pylori infection, and subjects with high levels of both $\mathrm{H}$. pylori antibody and PG II seem highly likely to have the highest activities of gastritis and highest degree of altered DNA methylation.

Regarding the $H$. pylori-related carcinogenesis, distinct pathways have been proposed for two histological types of gastric cancer: intestinal type and diffuse type [36]. Intestinal-type cancer is considered to develop in a multistep process starting from chronic active gastritis and progressing through chronic atrophic gastritis, intestinal metaplasia, and dysplasia [37]. In contrast, diffuse-type cancer develops in the stomach following chronic active inflammation without passing through the intermediate steps of atrophic gastritis or intestinal metaplasia. Of particular note, the activity of mucosal inflammation is proposed for a risk of diffuse-type cancer $[9,10,38]$. To date, studies about DNA methylation in gastric carcinogenesis have been mainly focused on the intestinal type [22, 23, 28, 39]. In reality, among $H$. pylorinegative subjects, including those with past infection, 
subjects with gastric cancer, particularly those with multiple gastric cancers, have stomach mucosae with more highly altered DNA methylation than those without $[22,39]$. The finding in this report, in contrast, showed that the degree of altered DNA methylation parallels the activity of gastritis and appears to be deeply involved in active inflammationmediated carcinogenesis leading to the development of diffuse-type cancer. Furthermore, recent evidence indicates that alterations in the DNA methylation of various gene regions including the CDH1 (E-cadherin) promoter are frequently observed in diffuse-type cancer and are deeply involved in the development of this type of gastric cancer [40, 41].

Some limitations in the study methods must be considered when interpreting the present findings. First, differences in DNA methylation levels among all stratified groups were insufficient to show statistical significance because of the relatively small number of samples. However, methylation levels were consistently altered in the same manner among CGI hypermethylation or hypomethylation of repetitive elements along with increases in serum marker levels. We thus believe that DNA methylation levels are tightly correlated with both markers reflecting the activity of gastritis. Second, some clinical factors that affect DNA methylation alteration might not have been completely excluded. For example, Epstein-Barr virus infection is known to enhance the DNA methylation in gastric cancer tissues [23]. However, H. pylori infection is a major factor in the alteration of DNA methylation in stomach mucosae of healthy volunteers, as repeatedly shown in previous studies [22, 42]. Indeed, the CGI methylation level was almost zero among $H$. pylori-negative subjects in the present study. Third, the small amount of samples led to no histological evaluations on $\mathrm{H}$. pylorirelated gastritis including the degree of intestinal metaplasia or stromal inflammatory cells. Although those mucosal findings in biopsy samples could affect the alteration in DNA methylation [43], the degree of the alterations might be modest or dependent on genes as suggested in some previous reports $[34,44]$. In contrast, alterations in DNA methylation in parallel with the severity of gastritis were considerable and consistently observed in the present study. Thus, we believe that bias due to those factors on the present results might be marginal.

In conclusion, the results of this study strongly indicate that DNA methylation levels in stomach mucosae are closely correlated with inflammatory activity in stomach mucosae. In terms of $H$. pylori-related stomach carcinogenesis, highly altered DNA methylation correlated with highly active gastritis appears to represent one of the relevant molecular mechanisms underlying the development of diffuse-type gastric cancer. The evaluation of altered DNA methylation in stomach mucosa is thus likely to be useful in predicting the risk of gastric cancer, particularly for diffuse-type cancer. We are now carrying out a longterm follow-up study of subjects from the present study for cancer development.

Acknowledgments This work was supported by Grant-in-Aid for Scientific Research (c) of Japan Society for the Promotion of Science.

Conflict of interest All authors disclose no financial or personal relationships with other people or organizations that could inappropriately influence the present work.

\section{References}

1. Itzkowitz SH, Yio X. Inflammation and cancer IV. Colorectal cancer in inflammatory bowel disease: the role of inflammation. Am J Physiol Gastrointest Liver Physiol. 2004;287:G7-17.

2. Stauffer JK, Scarzello AJ, Jiang Q, Wiltrout RH. Chronic inflammation, immune escape and oncogenesis in the liver: a unique neighborhood for novel intersections. Hepatology. 2012. doi:10.1002/hep. 25674

3. Macarthur M, Hold GL, El-Omar EM. Inflammation and Cancer II. Role of chronic inflammation and cytokine gene polymorphisms in the pathogenesis of gastrointestinal malignancy. Am J Physiol Gastrointest Liver Physiol. 2004;286:G515-20.

4. Lu H, Ouyang W, Huang C. Inflammation, a key event in cancer development. Mol Cancer Res. 2006;4:221-33.

5. Rutter M, Saunders B, Wilkinson K, Rumbles S, Schofield G, Kamm M, et al. Severity of inflammation is a risk factor for colorectal neoplasia in ulcerative colitis. Gastroenterology. 2004; 126:451-9.

6. Chen CJ, Yang HI, Su J, Jen CL, You SL, Lu SN, et al. Risk of hepatocellular carcinoma across a biological gradient of serum hepatitis B virus DNA level. JAMA. 2006;295:65-73.

7. Yang HI, Yeh SH, Chen PJ, Iloeje UH, Jen CL, Su J, et al. Associations between hepatitis B virus genotype and mutants and the risk of hepatocellular carcinoma. J Natl Cancer Inst. 2008;100:1134-43.

8. Correa P, Houghton J. Carcinogenesis of Helicobacter pylori. Gastroenterology. 2007;133(659-67):2.

9. Nomura A, Stemmermann GN, Chyou PH, Kato I, Perez-Perez GI, Blaser MJ. Helicobacter pylori infection and gastric carcinoma among Japanese Americans in Hawaii. N Engl J Med. 1991;325:1132-6.

10. Yanaoka K, Oka M, Mukoubayashi C, Yoshimura N, Enomoto S, Iguchi $\mathrm{M}$, et al. Cancer high-risk subjects identified by serum pepsinogen tests: outcomes after 10-year follow-up in asymptomatic middle-aged males. Cancer Epidemiol Biomarkers Prev. 2008; $17: 838-45$.

11. Loffeld RJ, Werdmuller BF, Kusters JG, Kuipers EJ. IgG antibody titer against Helicobacter pylori correlates with presence of cytotoxin associated gene A-positive $H$. pylori strains. FEMS Immunol Med Microbiol. 2000;28:139-41.

12. Plebani M, Basso D, Cassaro M, Brigato L, Scrigner M, Toma A, et al. Helicobacter pylori serology in patients with chronic gastritis. Am J Gastroenterol. 1996;91:954-8.

13. Yanaoka K, Oka M, Yoshimura N, Mukoubayashi C, Enomoto S, Iguchi M, et al. Risk of gastric cancer in asymptomatic, middleaged Japanese subjects based on serum pepsinogen and Helicobacter pylori antibody levels. Int J Cancer. 2008;123:917-26.

14. Ito M, Yoshihara M, Takata S, Wada Y, Matsuo T, Boda T, et al. Serum screening for detection of high-risk group for early-stage 
diffuse type gastric cancer in Japanese. J Gastroenterol Hepatol. 2012;27:598-602.

15. Robertson KD. DNA methylation and human disease. Nat Rev Genet. 2005;6:597-610.

16. Feinberg AP, Ohlsson R, Henikoff S. The epigenetic progenitor origin of human cancer. Nat Rev Genet. 2006;7:21-33.

17. Ushijima T. Epigenetic field for cancerization. J Biochem Mol Biol. 2007;40:142-50.

18. Jones PA, Baylin SB. The epigenomics of cancer. Cell. 2007;128(683-69):2.

19. Ushijima T. Detection and interpretation of altered methylation patterns in cancer cells. Nat Rev Cancer. 2005;5:223-31.

20. Howard G, Eiges R, Gaudet F, Jaenisch R, Eden A. Activation and transposition of endogenous retroviral elements in hypomethylation induced tumors in mice. Oncogene. 2008;27:404-8.

21. Roman-Gomez J, Jimenez-Velasco A, Agirre X, Cervantes F, Sanchez J, Garate L, et al. Promoter hypomethylation of the LINE-1 retrotransposable elements activates sense/antisense transcription and marks the progression of chronic myeloid leukemia. Oncogene. 2005;24:7213-23.

22. Maekita T, Nakazawa K, Mihara M, Nakajima T, Yanaoka K, Iguchi $\mathrm{M}$, et al. High levels of aberrant DNA methylation in Helicobacter pylori-infected gastric mucosae and its possible association with gastric cancer risk. Clin Cancer Res. 2006;12: 989-95.

23. Enomoto S, Maekita T, Tsukamoto T, Nakajima T, Nakazawa K, Tatematsu M, et al. Lack of association between $\mathrm{CpG}$ island methylator phenotype in human gastric cancers and methylation in their background non-cancerous gastric mucosae. Cancer Sci. 2007;98:1853-61.

24. Kondo Y, Kanai Y, Sakamoto M, Mizokami M, Ueda R, Hirohashi S. Genetic instability and aberrant DNA methylation in chronic hepatitis and cirrhosis - a comprehensive study of loss of heterozygosity and microsatellite instability at 39 loci and DNA hypermethylation on $8 \mathrm{CpG}$ islands in microdissected specimens from patients with hepatocellular carcinoma. Hepatology. 2000;32:970-9.

25. Issa JP, Ahuja N, Toyota M, Bronner MP, Brentnall TA. Accelerated age-related $\mathrm{CpG}$ island methylation in ulcerative colitis. Cancer Res. 2001;61:3573-7.

26. Shen L, Kondo Y, Rosner GL, Xiao L, Hernandez NS, Vilaythong J, et al. MGMT promoter methylation and field defect in sporadic colorectal cancer. J Natl Cancer Inst. 2005;97:1330-8.

27. Saito S, Kato J, Hiraoka S, Horii J, Suzuki H, Higashi R, et al. DNA methylation of colon mucosa in ulcerative colitis patients: correlation with inflammatory status. Inflamm Bowel Dis. 2011;17:1955-65.

28. Yoshida T, Yamashita S, Takamura-Enya T, Niwa T, Ando T, Enomoto S, et al. Alu and Satalpha hypomethylation in Helicobacter pylori-infected gastric mucosae. Int $\mathrm{J}$ Cancer. 2011;128:33-9.

29. Ichinose M, Miki K, Furihata C, Kageyama T, Hayashi R, Niwa $\mathrm{H}$, et al. Radioimmunoassay of serum group I and group II pepsinogens in normal controls and patients with various disorders. Clin Chim Acta. 1982;126:183-91.
30. Kaneda A, Kaminishi M, Sugimura T, Ushijima T. Decreased expression of the seven ARP2/3 complex genes in human gastric cancers. Cancer Lett. 2004;212:203-10.

31. Mardh E, Mardh S, Mardh B, Borch K. Diagnosis of gastritis by means of a combination of serological analyses. Clin Chim Acta. $2002 ; 320: 17-27$.

32. Nishida N, Nagasaka T, Nishimura T, Ikai I, Boland CR, Goel A. Aberrant methylation of multiple tumor suppressor genes in aging liver, chronic hepatitis, and hepatocellular carcinoma. Hepatology. 2008;47:908-18.

33. Arasaradnam RP, Khoo K, Bradburn M, Mathers JC, Kelly SB. DNA methylation of ESR-1 and N-33 in colorectal mucosa of patients with ulcerative colitis (UC). Epigenetics. 2010;5:422-6.

34. Shin CM, Kim N, Jung Y, Park JH, Kang GH, Kim JS, et al. Role of Helicobacter pylori infection in aberrant DNA methylation along multistep gastric carcinogenesis. Cancer Sci. 2010;101:1337-46.

35. Guarner J, Herrera-Goepfert R, Mohar A, Sanchez L, Halperin D, Ley C, et al. Interobserver variability in application of the revised Sydney classification for gastritis. Hum Pathol. 1999;30:1431-4.

36. Nardone G, Rocco A, Malfertheiner P. Review article: Helicobacter pylori and molecular events in precancerous gastric lesions. Aliment Pharmacol Ther. 2004;20:261-70.

37. Correa P. Human gastric carcinogenesis: a multistep and multifactorial process-First American Cancer Society Award Lecture on Cancer Epidemiology and Prevention. Cancer Res. 1992;52:6735-40.

38. Watanabe M, Kato J, Inoue I, Yoshimura N, Yoshida T, Mukoubayashi $\mathrm{C}$, et al. Development of gastric cancer in nonatrophic stomach with highly active inflammation identified by serum levels of pepsinogen and Helicobacter pylori antibody together with endoscopic rugal hyperplastic gastritis. Int J Cancer. 2012;131:2632-42.

39. Nakajima $\mathrm{T}$, Maekita $\mathrm{T}$, Oda $\mathrm{I}$, Gotoda $\mathrm{T}$, Yamamoto $\mathrm{S}$, Umemura $\mathrm{S}$, et al. Higher methylation levels in gastric mucosae significantly correlate with higher risk of gastric cancers. Cancer Epidemiol Biomarkers Prev. 2006;15:2317-21.

40. Tamura G, Yin J, Wang S, Fleisher AS, Zou T, Abraham JM, et al. E-Cadherin gene promoter hypermethylation in primary human gastric carcinomas. J Natl Cancer Inst. 2000;92:569-73.

41. Ushijima T, Sasako M. Focus on gastric cancer. Cancer Cell. 2004;5(121-12):5.

42. Ando T, Yoshida T, Enomoto S, Asada K, Tatematsu M, Ichinose $\mathrm{M}$, et al. DNA methylation of microRNA genes in gastric mucosae of gastric cancer patients: its possible involvement in the formation of epigenetic field defect. Int J Cancer. 2009;124: 2367-74.

43. Park SY, Yoo EJ, Cho NY, Kim N, Kang GH. Comparison of $\mathrm{CpG}$ island hypermethylation and repetitive DNA hypomethylation in premalignant stages of gastric cancer, stratified for Helicobacter pylori infection. J Pathol. 2009;219:410-6.

44. Hosoya K, Yamashita S, Ando T, Nakajima T, Itoh F, Ushijima $\mathrm{T}$. Adenomatous polyposis coli $1 \mathrm{~A}$ is likely to be methylated as a passenger in human gastric carcinogenesis. Cancer Lett. 2009; 285:182-9. 